\title{
Telling stories about our research
}

\section{Emma Weitkamp}

Abstract

Keywords

The academic journal paper has been around for several hundred years and during that time has seen shifts in style and structure. This editorial explores the traditional research paper and considers whether thinking about the research paper as a story, provides insights into style and structure that would make research both more transparent and more readable.

Professionalism, professional development and training in science communication; Scholarly communication; Science writing

In preparing a session on storytelling for my MSc Science Communication students I recently came across an interesting blog post by Tom Houslay [2015] suggesting that we apply storytelling principles in writing scientific research papers. This is not necessarily a new idea, as others [e.g. Feamster, 2013; Higher education network, 2015] have advocated that researchers identify a story that they wish their paper to tell before embarking on the writing process. Feamster is not suggesting that we make up a story or that we twist the results to meet a specific message; he suggests that in fact the story may change as the writing develops. He is pointing out the importance of clarity and focus. As he says 'there are many stories that a paper could tell, and it's important to think about what that story should be' (np).

Scientific papers have been around for at least 350 years; not surprisingly approaches to writing scientific papers have changed over this period. In fact, scientists (particularly English ones) used to use a wider variety of writing styles. Gross et al. [2002] identified quite a wide range of writing styles in $18^{\text {th }}$ Century English scientific scholarly works, including both epistolary (letter format) and narrative forms (including the use of the personal pronoun). However, it seems that throughout the $20^{\text {th }}$ Century, the more impersonal and expository (explanatory) style of the French and German scientific publishing traditions came to dominate and with this the rise of the passive voice, extensive use of noun phrases (a group of words that together function as a noun) and over description. Langdon-Neuner [2007] argues that this change is linked to changes in medical practice, which shifts to consider diseases and groups of patients, rather than individual cases; as a result writing style becomes more informational and moves way from narrative accounts. Lexical analysis shows that it is not just the writing genre that has changed, but also the complexity of the writing (e.g. complex grammar, use of specialist words and jargon) [Russell, 2009].

This means, of course, that becoming indoctrinated as a researcher means not only learning a corpus of knowledge, but also the language and communication 
conventions used by that specific discipline (or sub-discipline). To be a successful researcher, you must master the primary communication tool used by scientists: the research paper. While there is some discussion, particularly amongst journal editors, about the appropriateness of 'the research paper' format in the internet age, I will take for granted that the research paper will be around for a few years yet and consider whether we might improve upon it by looking back at its roots and sideways at other genre to see what we might learn.

Although the structure of research papers varies a little within disciplines, they largely conform to the following structure: context (introduction and/or literature review), research question, methods, results, discussion and conclusion. Houslay suggests that the principles of the 8 step story circle could be applied to research papers, whereby the story of research is framed through: a protagonist (the researcher(s)), exploring something (e.g. the research question or problem) that is unknown (entering into uncharted territory). You then encounter problems (e.g. methods ) before meeting with a revelation (he calls it a goddess) and then embarking on some form of interpretation (e.g. figuring out what the results mean) and placing it within the context of what we already know (i.e. how does it relate to other research in the field) and draw your conclusions. I've rephrased Houslay a little in summarising the above, but to me the 8 elements look remarkably like the traditional structure of many research papers:

1. Protagonist (the writer- and here we can discuss voice)

2. Explores something (the research question, perhaps with a brief introduction)

3. Entering uncharted territory (literature/context)

4. How the protagonist explored it (methods)

5. Revelation (data analysis)

6. Protagonists' interpretation of these data (results - but the protagonist is usually missing in this presentation)

7. How this changes what we know already (discussion)

8. Implications (conclusion)

When framed as I have suggested above, the main change seems to be in 'voice' in which the story is written. If we (the researchers) are going to be protagonists, then we surely can't write our papers in the third person. Russell [2009] points out that the passive voice removes the agency of the researchers, making the results appear to be 'something nature does' (p. 19). As a result using the passive voice means that 'a lot of the personal, the social, and the messily contingent about gathering data are edited from all science reports with the passive voice' [Russell, 2009, p. 20]. Langdon-Neuner [2007] argues that emotion and first person writing were dropped from scientific discourse 'to impress their readership with their objectivity and authority through prolixity' (p. 71) and that this style has remained as a way of highlighting their status. As she says, 'I find it hard to avoid the conclusion that the central reason for scientists, who we assume are clever people, writing in such an obscure style is to persuade the confused reader that they are indeed clever people.' [Langdon-Neuner, 2007, p. 69]. Another argument for a move toward first person 
writing of research papers is that it would help to clarify authorship roles on multi-authored research studies (which would probably be a good thing, and would be more transparent than the current trend of some journals to ask authors to provide a summary of who did what at the end of the paper). JCOM would certainly be happy to consider papers written in this more open and transparent voice (while maintaining the rigour of research of course). The main argument against first person writing seems to be a desire amongst the scientific/research community to maintain the 'objectivity' of the research process. While clearly I do not advocate research that is biased or designed to come up with a specific result, I would question whether objectivity is really possible in any research process. And I also agree with Biomedical editor ${ }^{1}$ that there can be good reasons to use the passive voice (Biomedical Editor provides some clear examples).

So where does this leave the traditional research paper? Having read many research papers in my time as Editor of JCOM, I have concluded that a more transparent and personal writing style not only enlightens the reader as to the motivations of the writer, but also makes it clear who has been involved in the process and how as well as allowing the reader to more clearly see the challenges faced in the process. There are examples of engagingly written research papers they explore the gaps in knowledge and how your research fits into these spaces (what Houslay calls 'your call to adventure'). They do not seek to use an obfuscatory style to enhance the authority of the writer. Instead, clear writing allows your brilliant ideas to shine through and makes your writing accessible to a wider audience (though perhaps still not a popular one). And I most certainly do not suggest we turn the research paper on its head and write it as a news story (e.g. in the inverted pyramid format). While such an approach might indeed make the findings clear and noticeable, I'm not sure that such a structure lends itself to thoughtful evaluation (by the reader) of the data and conclusions. After all, a sceptical researcher should be considering whether they agree with the authors' interpretation.

Many other forms of writing arrive at conclusions only after presenting evidence; thoughtful, carefully constructed arguments are made that take the reader on a journey allowing them to evaluate evidence and decide whether they agree (or not) with the authors conclusions. The research paper format, as one style of writing, allows you to take the reader on such a journey - by telling them a story. But, as Nick Feamster points out, what matters most is the clarity with which you present your ideas. If the reader can't understand what you are trying to say, whether because you use complex jargon or simply don't structure your argument clearly, your message is lost. Perhaps even more fundamentally 'muddy writing often reflects muddy thinking' [Feamster, 2013, italics in original]. And no journal will publish muddy thinking.

\footnotetext{
${ }^{1}$ http:/ / www.biomedicaleditor.com/passive-voice.html.
} 
Feamster, N. (2013). Storytelling 101: Writing tips for academics. URL: http://greatre search.org/2013/10/11/storytelling-101-writing-tips-for-academics/ (visited on 8th February 2016).

Gross, A. G., Harmon, J. E. and Reidy, M. S. (2002). Communicating Science : The Scientific Article from the $17^{\text {th }}$ Century to the Present: The Scientific Article from the 17th Century to the Present. Oxford, U.S.A.: Oxford University Press.

Higher education network (3rd January 2015). How to get published in an academic journal: top tips from editors. Journal editors share their advice on how to structure a paper, write a cover letter and deal with awkward feedback from reviewers. URL: http://www. theguardian.com/education/2015/jan/03/how-t o-get-published-in-an-academic-journal-top-tips-from-editors (visited on 8th February 2016).

Houslay, T. (2015). Applying the story circle to academic writing. URL: http: //tomhous lay.com/2016/02/05/applying-the-story-circle-to-academic-writing/ (visited on 7th February 2016).

Langdon-Neuner, E. (2007). 'Scientific Writing'. The Write Stuff 18 (2), pp. 69-72. URL:

http://www . emwa.org/documents/journal/TWS/TWS\%202009\%202\%2018.pdf (visited on 8th March 2016).

Russell, N. (2009). Communicating Science: Professional, Popular, Literary. Cambridge, U.K.: Cambridge University Press.

Author

Dr. Emma Weitkamp is an Associate Professor in Science Communication at the University of the West of England, Bristol where she teaches on an MSc in Science Communication and provides training in science communication for practitioners and Ph.D. students. Emma is also Editor in Chief of JCOM.

E-mail: Emma.Weitkamp@uwe.ac.uk.

\section{How to cite}

Weitkamp, E. (2016). ‘Telling stories about our research'. JCOM 15 (02), E. 